\title{
Management of insect pests using semiochemical traps
}

C.A. Baroffio ${ }^{1, a}$, V. Guibert 1 , P. Richoz ${ }^{1}$, A. Rogivue 1 , A.K. Borg-Karlsson², J. Cross ${ }^{3}$, M. Fountain 3 , D. Hall ${ }^{4}$, B. Ralle ${ }^{5}$, L. Sigsgaard 6 , N. Trandem ${ }^{7}$ and A. Wibe ${ }^{8}$

${ }^{1}$ Agroscope IPS, Conthey, Switzerland; ${ }^{2}$ KTH Royal Inst. of Techn., Stockholm, Sweden; ${ }^{3}$ East Malling Research, Kent, United Kingdom; ${ }^{4}$ Natural Resources Institute, Kent, United Kingdom; 5Latv. Plant Prot Res. Centre, Riga, Latvia; 6 University of Copenhagen, Frederiksberg, Denmark; ${ }^{7 B i o f o r s k, ~ A ̊ s, ~ N o r w a y ; ~}{ }^{8}$ Bioforsk, Tingvoll, Norway.

\begin{abstract}
In the absence of effective control measures, the strawberry blossom weevil (Anthonomus rubi) (SBW) and the raspberry beetle (Byturus tomentosus) (RB) cause large $(10->80 \%)$ losses in yield and quality in organically grown raspberry. Attractive lures for both pests were combined into a single multitrap for the economical management of both of these pests at the same time. This is one of the first approaches to pest management of non-lepidopteran insect pests of horticultural crops using semiochemicals in the $\mathrm{EU}$, and probably the first to target multiple species from different insect orders. The aim is to develop optimized lures and cost-effective trap designs for mass trapping and to determine the optimum density and spatial and temporal patterns of deployment of the traps for controlling these pests by mass trapping. The combination between an aggregation pheromone that attracts Anthonomus rubi and a raspberry flower volatile that attracts Byturus tomentosus seems to be the best combination.
\end{abstract}

Keywords: Anthonomus rubi, Byturus tomentosus, semiochemical trap, raspberry

\section{INTRODUCTION}

The strawberry blossom weevil called SBW (Anthonomus rubi Herbst) and the raspberry beetle called RB (Byturus tomentosus DeGeer) are two important pests in raspberries in northern and central Europe. They cause yield and quality losses up to $80 \%$. The strawberry blossom weevil, a 3- to $3.5-\mathrm{mm}$ beetle, overwinters as adult, begins activity in April and mates in May (Stäubli and Höhn, 1989) In Switzerland, the pest is mainly present in the crops in the mountains. It feeds on raspberry leaves and flowers. The female lays 20-30 eggs in the flower buds and cuts them after. The SBW can destroy as many buds as egg laid: 65 to $85 \%$ of the cut buds contains only 1 egg (Popov, 1996). In Switzerland, the SBW can destroy $30 \%$ of the flower buds in a crop and in Norway, it can be $80 \%$ (Nina Trandem, pers. commun.). The actual economical damage threshold is $10 \%$ of the flower trusses damaged by a control of 100 trusses $1000 \mathrm{~m}^{-2}$ (Linder et al., 2012). The raspberry beetle, a 4- to 5-mm beetle, overwinters as adult, begins activity in April and mates in May (Antonin, 1984). Females lay 100 eggs in flowers or young fruits with an average of 1-3 eggs day $^{-1}$. The economical damage threshold is 1 adult for 100 flower trusses. With the Rebell traps bianco, the threshold is 10 catches trap ${ }^{-1}$ week $^{-1}$. Damage is caused by larval development in fruits for B. tomentosus. Presently, there are only chemical treatments to control the strawberry blossom weevil and a semiochemical trap has been developed to control the raspberry beetle (Baroffio et al., 2012; Birch et al., 2009). Alternative methods of control are required by growers, organic or not, and by consumers. "Softpest Multitrap" is a EU FP7 Core Organic 2 project (2012-14) with the aim to develop in strawberry a common trap against Lygus rugulipennis and Anthonomus rubi and in raspberry a common trap against Byturus tomentosus and Anthonomus rubi. Experiments were done in six countries to find and to test a common semiochemical trap for both pests in each crop (Wibe et al., 2012). The attractant for $A$. rubi is composed of the male aggregation pheromone and a plant

${ }^{a}$ E-mail: catherine.baroffio@agroscope.admin.ch 
volatile. The attractant for $B$. tomentosus is a raspberry flower volatile. Lure combination trials were performed in Switzerland and in Norway in raspberry to find the best combination. The Swiss results 2012-2014 are presented here.

\section{MATERIALS AND METHODS}

The trials were conducted between 2012 and 2014 in Switzerland. The plots were located in Wallis, in the mountains (Table 1). Green bucket traps with white cross-vanes and a bee excluder grid were employed (Figure 1). Trapping was carried out from April to October 2013 and 2014. Captures were checked every week and lures changed every 4-8 weeks. The traps were filled with water containing Triton X-100 $(10 \mathrm{~mL}$ Triton in $10 \mathrm{~L}$ water). Three different trials were initiated.

Table 1. Plot and crop description of the Swiss trials between 2012 and 2014.

\begin{tabular}{lcccccccc}
\hline Year & Location & $\begin{array}{c}\text { Altitude } \\
(\mathbf{m})\end{array}$ & $\begin{array}{c}\text { Surface } \\
\left(\mathbf{m}^{2}\right)\end{array}$ & $\begin{array}{c}\text { Plantation } \\
\text { year }\end{array}$ & Mypex & $\begin{array}{c}\text { Plantation } \\
\text { density }\left(\mathbf{m}^{2}\right)\end{array}$ & Trial \\
\hline 2012 & Bruson & 1060 & 1000 & 2005 & yes & 3 & $\mathrm{Nr} 1$ & Trap height \\
2012 & St Sébastien & 1000 & 3000 & 2004 & no & 3 & $\mathrm{Nr} 1$ & Trap height \\
2012 & Les Bioleys & 1000 & 2000 & 2005 & no & 3 & $\mathrm{Nr} 1$ & Trap height \\
2013 & Bruson & 1060 & 1000 & 2005 & yes & 3 & $\mathrm{Nr} 2$ & Trap design \\
2013 & Chardonney & 1000 & 1500 & 2006 & yes & 3 & $\mathrm{Nr3}$ & Lure combination \\
2014 & Salins & 750 & 3000 & 2009 & no & 3 & $\mathrm{Nr} 3$ & Lure combination \\
\hline
\end{tabular}
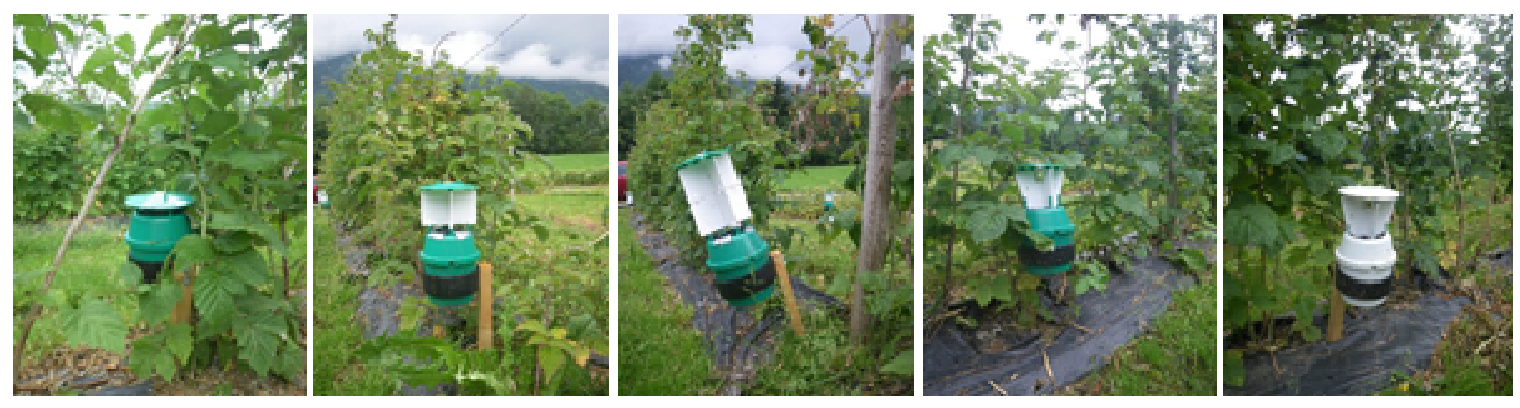

Figure 1. Description of the 5 types of traps. From left to right: green bucket without vanes; green bucket with square white vanes; green bucket with double height square vanes; green bucket with trapezoidal white vanes (standard trap); white bucket with white trapezoidal white vanes.

\section{Trial 1: trap height}

Three different heights were compared: $0.00,0.75$ and $1.50 \mathrm{~m}$. Traps were baited with the standard lure combination for Anthonomus rubi in 2012 in 3 different plots within a line and an interval of 3 meters between each trap. There were 3 replicates in each plot, each time in a different position. Traps were checked weekly.

\section{Trial 2: trap design}

Trap design was tested in Bruson in 2013. Different colours and shapes were tested: a) without vanes, b) square vanes, c) double height square vanes, d) trapezoidal vanes (standard trap), e) standard trap completely white (Figure 1). Traps were baited with the lures attracting both insects: a raspberry flower volatile (rv) to attract RB, and an aggregation pheromone and a strawberry flower volatile (pv2) to attract the SBW. Traps were set on week 25 (2013) with 6 replicates. Traps were set randomly on each of the 6 lines with a 7-m distance between the traps and a $2.15-\mathrm{m}$ width between the lines. Traps were checked weekly. 


\section{Trial 3: lure combination}

Traps with different lure combinations were tested in 2013 and 2014. Each trap had different lure combinations (Table 2). The attractant for $A$. rubi was composed of the male aggregation pheromone and a plant volatile (aggregation pheromone was composed of 100 $\mu \mathrm{L}$ normal 1:4:1 blend of grandlure 1: grandlure; 2: lavandulol, and the plant volatile (PV2) was composed of $200 \mathrm{mg}$ of strawberry flower volatile) (Cross et al., 2006; Innocenzi et al., 2001; Wibe et al., 2014). The attractant for B. tomentosus (RV) was composed of $2 \mathrm{~g}$ of raspberry flower volatile (Birch et al., 2009; Woodford et al., 2003). Six replicates of each combination were randomly placed in the plots. The traps were placed with a distance of 10 $\mathrm{m}$ between them. The catches were counted and identified, and also sexed for A. rubi, at weekly intervals. Cut bud damage caused by $A$. rubi was assessed for 20 inflorescences around each trap. Damage inflicted by $B$. tomentosus was assessed by counting larvae in 120 fruits collected randomly in the plot at 3 dates: begin, mid and end of harvest (wk 31: phenological stage 89 - 1st fruits coloured; wk 32: phenological stage $839-30 \%$ fruits harvested; wk 33: phenological stage $897-70 \%$ fruits harvested). Statistics were executed with the R software (Kruskal-Wallis and pairwise multiple comparison).

Table 2. Different lure combination tested in 2013 and 2014.

\begin{tabular}{lcc}
\hline Combination & Target & Year \\
\hline Aggregation pheromone (Agg ph) + PV2 (=standard combination) & A. rubi & 2013 \\
& & 2014 \\
PV2 & A. rubi & 2014 \\
Rapsberry volatile (RV) & B. tomentosus & 2013 \\
& & 2014 \\
RV+Agg ph + PV2 & A. rubi & 2013 \\
& B. tomentosus & 2014 \\
RV + PV2 & A. rubi & 2013 \\
RV + Agg ph & B. tomentosus \\
Aggregation pheromone (Agg ph) + PV2high + RV & A. rubi & 2013 \\
& B. tomentosus & 2014 \\
& A. rubi & 2014 \\
\hline
\end{tabular}

\section{RESULTS AND DISCUSSIONS}

\section{Trial 1: trap height}

The first SBW were caught in the weeks 17-20 (BBCH 45-47) before the development of the flower buds (Figure 2). SBW was more attracted by the traps set on the ground (Kruskal-Wallis, $\mathrm{p}<0,001$ ) than traps put at 0.75 and $1.50 \mathrm{~m}$. RB was caught at the 3 heights without significant difference. The results in Norway (not shown here) give a similar pattern. This experiment shows that for effective trapping the trap must be set on the ground early in the season to catch the overwintering generation of SBW and the flight of the RB before the flowering period of strawberry.

\section{Trial 2: trap design}

Regarding the designs and colors of the traps, SWD showed no significant preference between variants, but the number of catches were low in Switzerland. The standard trap with trapezoidal vanes and the model with square vanes captured both insects, while the double-height model captured many weevils and a few Byturus, while models 1 (without vanes) and 5 (completely white) did not capture Byturus (Figure 3). The standard model was appropriate to test combinations of lures. 

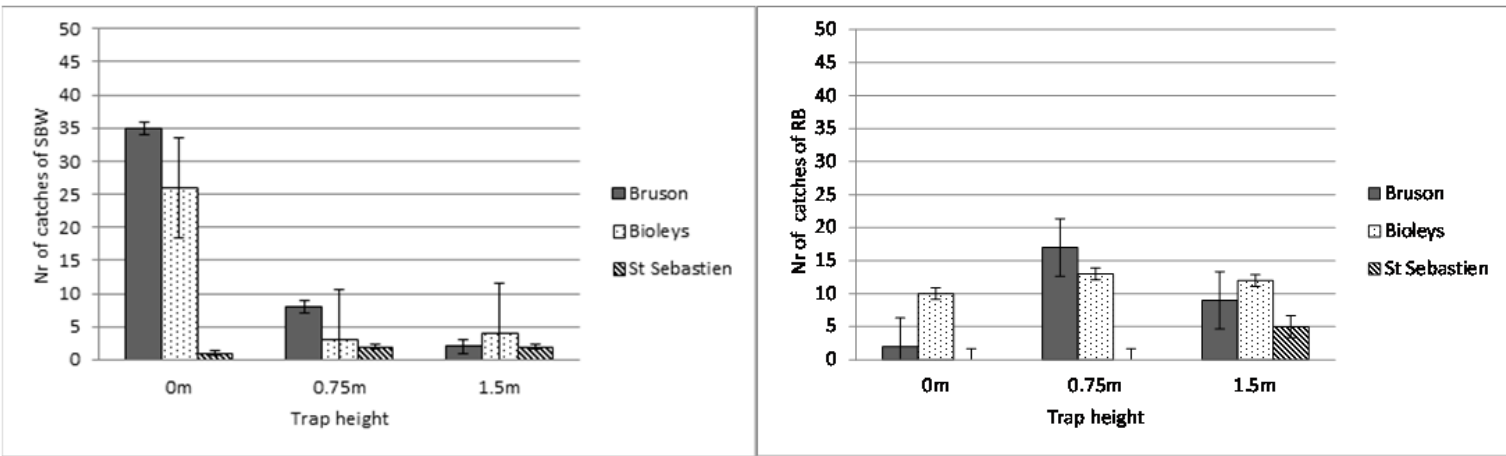

Figure 2. Relationship between SBW abundance and the height of traps in three Swiss locations (left). Relationship between RB abundance and the height of traps in three Swiss locations in 2012 in raspberry. Average of 3 replicates per plot.

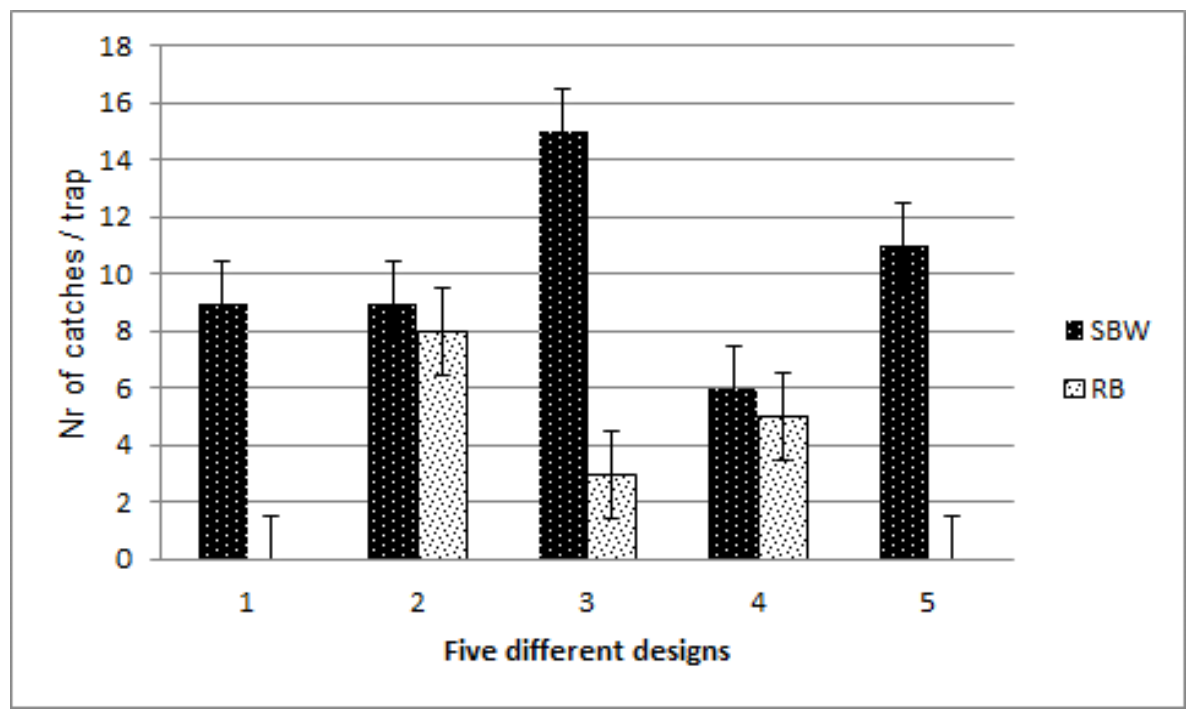

Figure 3. Relationship between SBW and RB abundance in five different traps designs: 1 : green bucket without vanes; 2: green bucket with square white vanes; 3: green bucket with double height square vanes; 4: green bucket with trapezoidal white vanes (standard trap); 5: white bucket with white trapezoidal white. Average of 6 replicates in Bruson in 2013.

\section{Trial 3: lure combination}

Table 3 shows the catches in 2013 and 2014 for SBW and RB based on the different combinations of lures. In 2014, catches were very low. The results of 2013 and 2014 show that the combination "rv + agg ph" is a suitable combination to attract both insects. This combination is significantly different from the combinations "rv" and "rv + pv2" for SBW. Combining lure types did not influence damage caused by SBW (Kruskal-Wallis $p=0.84$ ). Damage increased over time between the beginning and the middle of flowering period (Figure 4): at BBCH 63, corresponding to over 30\% of open flowers, the damage reached 50 buttons cut per 100 inflorescences. The RB catches are influenced by the combination of lures (Kruskal-Wallis $\mathrm{p}=0.0082$ ). As to their damage, the combination "rv + agg $\mathrm{ph}$ " was associated with a statistically non-significant reduction in fruit damage in fruit at the end of harvest. The Swiss results are similar to the Norwegian results (not shown in this publication) although the latter were based on a larger population of insects caught in the traps. Our results show that it is possible to attract two different pests in the same trap and that the best combination is the one that includes the attractive floral for the Byturus (rv) 
and aggregation pheromones (one of the two components the standard mixture) for SBW, either for the number of catches or the estimate of the damage.

Table 3. Abundances of SBW and RB in standard traps in 2013 (St Sebastien) and 2014 (Saline).

\begin{tabular}{lcccc}
\hline \multirow{2}{*}{ Lure combination } & \multicolumn{2}{c}{ SBW } & \multicolumn{2}{c}{ RB } \\
\cline { 2 - 5 } & $\mathbf{2 0 1 3}$ & $\mathbf{2 0 1 4}$ & $\mathbf{2 0 1 3}$ & $\mathbf{2 0 1 4}$ \\
\hline agg ph + pv2 & 13 & 4 & 18 & 0 \\
Rv & 3 & 1 & 68 & 8 \\
r + agg ph + pv2 & 8 & 1 & 67 & 3 \\
pv + pv2 & 0 & - & 52 & - \\
rv + agg ph & 18 & 4 & 72 & 7 \\
pv2 & - & 0 & - & 0 \\
rb + agg ph + pv2 high & - & 3 & - & 8 \\
\hline
\end{tabular}

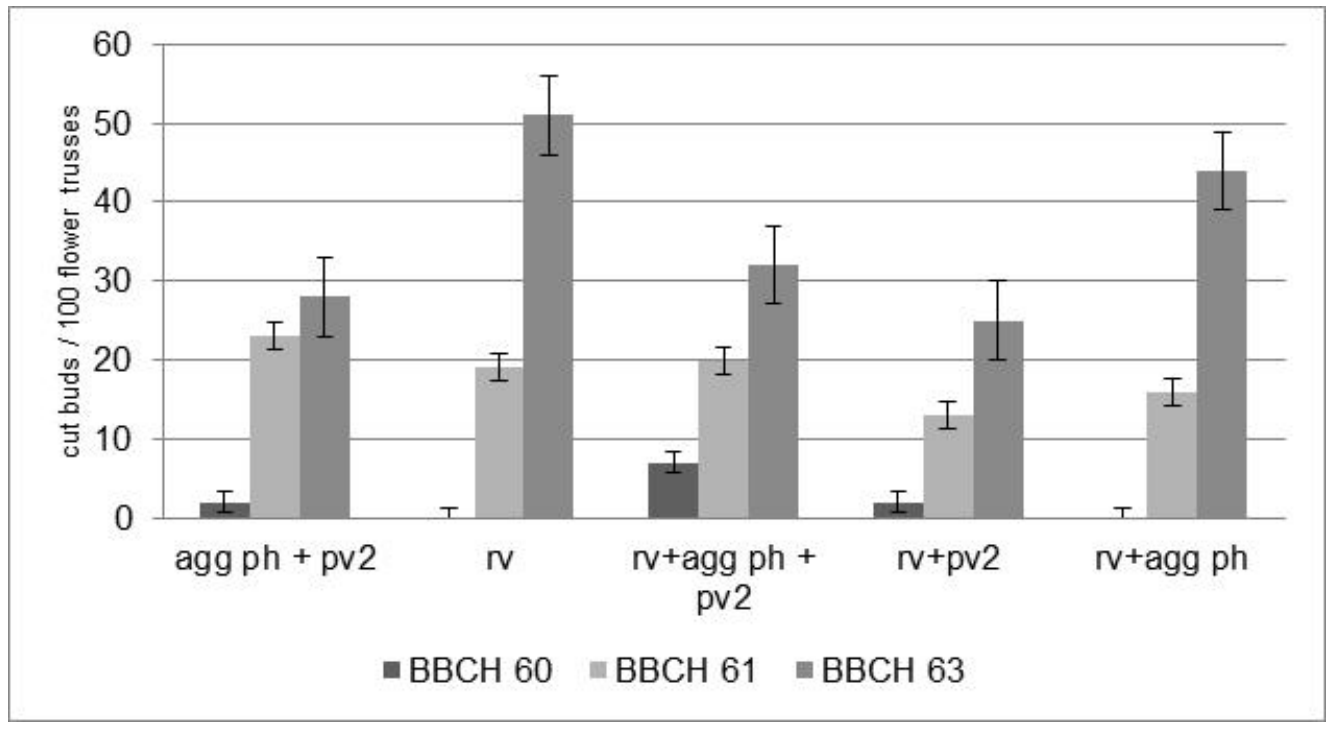

Figure 4. Relationship between the 5 different lure combinations and the damages assessed by the number of cut buds.

The design of the trap should be further improved: an aggregation of both pests was visually observed around the traps, indicating the lures attracted insects, but insects were not found in the traps after. The recorded damage in our tests is still over the economical threshold. We did not find a clear relationship between the number of catches and damage, suggesting that there is still scope to improve the attractiveness of the traps. Tests are underway to improve these aspects. However, this project provided interesting insights for the biological control using semiochemicals. When the plot with traps is compared to the control plot without any traps, we found a significant reduction of the damage in the plot with traps compared to the plot without traps (Figure 5). The Swiss and Norwegian results were similar, however, the Norwegian catches contained a higher abundance of both pests. 


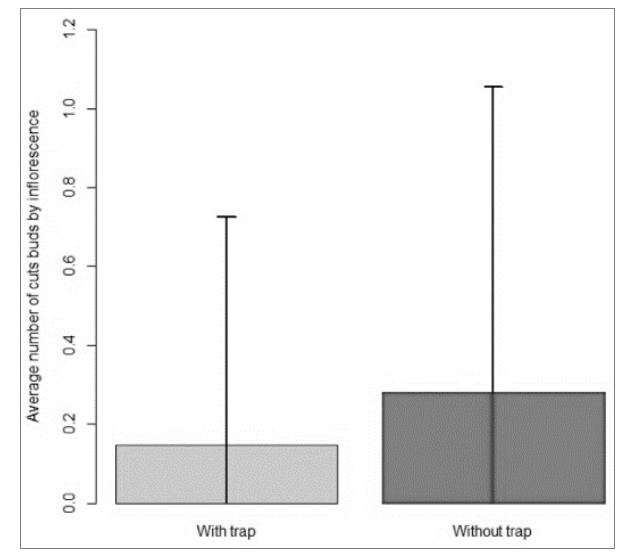

Figure 5. Relationship between damage assessment (number of cut buds) and the presence or not of traps in the plot.

\section{CONCLUSION}

These experimental trials showed the best trap in raspberry is a green bucket with white trapezoidal vanes and a bee exluder; it had to be put on the ground every $10 \mathrm{~m}$ on the plot at the begin of vegetation, in April, May (stage BBCH 45-47). The best lure combination is, according to our results, a combination of an aggregation pheromone of $A$. rubi (SBW) and a raspberry volatile which attracts $B$. tomentosus (RB). Lures must be changed after 8 weeks and traps are set in April to catch the overwintering generation of $A$. rubi to the end of the harvest. This innovative 3-year project explores new directions for a biological control with semiochemical traps. There is still some research to be done to find the right trap model and the optimal spatial arrangement of traps.

\section{ACKNOWLEDGEMENTS}

This study was made with the projet: "Softpest Multitrap". The authors thank the Swiss government for the project funding and the Core Organic project.

\section{Literature cited}

Antonin, P. (1984). Le ver des framboises, Byturus tomentosus. Rev. Suisse Vitic. Arboric. Hortic. 16, 103-105.

Baroffio, C., Trandem, N., and Birch, A.N.E. (2012). Efficiency of attractive traps in the fight against Byturus tomentosus in raspberries: examples from Switzerland, Scotland and Norway. Acta Hortic. 946, 213-217 http://dx.doi.org/10.17660/ActaHortic.2012.946.33.

Birch, A.N.E., Gordon, S., Shepherd, T., Griffith, W., Robertson, G., and Brennan, R. (2009). Development of semiochemical attractants, lures and traps for raspberry beetle, Byturus tomentosus at SCRI; from fundamental chemical ecology to testing IPM tools with growers. IOBC WPRS Bull. 41, 75-78.

Cross, J.V., Hall, D.R., Innocenzi, P.J., Hesketh, H., Jay, C.N., and Burgess, C.M. (2006). Exploiting the aggregation pheromone of strawberry blossom weevil Anthonomus rubi (Coleontera: Curculionidae): Part 2. Pest monitoring and control. Crop Prot. 25 (2), 155-166 http://dx.doi.org/10.1016/j.cropro.2005.04.004.

Innocenzi, P.J., Hall, D.R., and Cross, J.V. (2001). Components of male aggregation pheromone of strawberry blossom weevil, Anthonomus rubi herbst. (Coleoptera:Curculionidae). J. Chem. Ecol. 27 (6), 1203-1218 http://dx.doi.org/10.1023/A:1010320130073. PubMed

Linder, C., Baroffio, C., and Mittaz, C. (2012). New method for monitoring the damages of Anthonomus rubi on raspberry. Rev. Suisse Vitic. Arboric. Hortic. 44 (3), 162-166.

Popov, S.Y. (1996). Possibility of monitoring the population density of the strawberry blossom weevil, Anthonomus rubi Herbst (Coleoptera, Curculionidae), on strawberry by two methods: counting clipped buds and using pheromone. Entomol. Rev. (Engl. Transl.) 75, 104-109.

Stäubli, A., and Höhn, H. (1989). Anthonome du Fraisier et du Framboisier Antonomus rubi Hbst. (Agroscope).

Wibe, A., Baroffio, C., Borg-Karlson, A.K., Cross, J., Hall, D., Sigsgaard, L., and Trandem, N. (2012). Softpest Multitrap. Management of strawberry blossom weevil and European tarnished plant bug in organic strawberry 
and raspberry using semiochemical traps. Paper presented at: VII International Strawberry Symposium (Beijing China: ISHS).

Wibe, A., Borg-Karlson, A.K., Cross, J.V., Bichao, H., Fountain, M., Liblikas, M., and Sigsgaard, L. (2014). Combining 1,4-dimethoxybenzene, the major flower volatile of wild strawberry Fragaria vesca, with the aggregation pheromone of the strawberry blossom weevil Anthonomus rubi improves attraction. Crop Prot. 64, 122-128 http://dx.doi.org/10.1016/j.cropro.2014.06.016.

Woodford, A.T., Birch, A.N.E., Gordon, S., Griffith, W., Mc Nicol, J., and Robertson, G. (2003). Controlling raspberry beetle without insecticide. Integrated plant production in orchards. IOBC WPRS Bull. 26, 87-92. 
